\title{
Desenvolvimento e nutrição de mudas de acácia-negra (Acacia mearnsii de Wild. De Wild.) em substratos a base de cama de aviário
}

\author{
Development and nutrition of black wattle seedlings (Acacia mearnsii de Wild. De Wild.) in poultry \\ litter substrate
}

\author{
Raquel Rossi Ribeiro1, Flávia Gizele Konig Brun², Eleandro José Brun²*, Carlos César Mezzalira², \\ Taciana Frigotto ${ }^{2}$, Márcio Carlos Navroski ${ }^{3} \&$ Marcos Aurélio Mathias de Souza ${ }^{2}$ \\ ${ }^{1}$ Centro de Apoio ao Pequeno Agricultor, Verê, PR, Brasil. \\ ${ }^{2}$ Universidade Tecnológica Federal do Paraná, Dois Vizinhos, PR, Brasil. *Autor para correspondência: eleandrobrun@utfpr.edu.br. \\ ${ }^{3}$ Universidade do Estado de Santa Catarina, Lages, SC, Brasil.
}

Submissão: 16/12/2016 / Aceite: 30/10/2017

\begin{abstract}
RESUMO
Avaliou-se o desenvolvimento e o estado nutricional de mudas de Acacia mearnsii De Wild., produzidas em quatro diferentes substratos a base de cama de aviário, percentualmente distribuídos em: T1: 25CA:50S:25A; T2: 50CA25S25A; T3: 25CA75S e T4: 100SC (CA: cama de aviário; S: solo; A: areia; SC: substrato comercial), em tubetes de $125 \mathrm{~cm}^{3}$ e conduzidos em casa de vegetação / casa de sombra. Os melhores resultados, para as variáveis morfológicas altura da parte aérea, diâmetro do colo, número de folhas, massa seca de raízes e total, foram obtidos em substrato comercial e em misturas de $25 \%$ até $50 \%$ de cama de aviário com solo argiloso e areia. Os teores de $\mathrm{N}$ e Mg (parte aérea e raízes) e de P e K (parte aérea) não foram influenciados pelos substratos. Nas raízes, o $\mathrm{P}$ teve maior teor no tratamento com solo argiloso. O K, nas raízes, teve os maiores teores nos substratos com $25 \%$ a $50 \%$ de cama de aviário e no comercial. Para $\mathrm{Ca}$, os teores na parte aérea foram superiores ao das raízes, principalmente nos substratos com até $50 \%$ de cama de aviário. As raízes, para Ca, não se apresentaram influenciadas pelos tratamentos. Os substratos testados, em termos gerais, não influenciaram o status nutricional das mudas.
\end{abstract}

PALAVRAS-CHAVE: substratos alternativos, nutrição florestal, espécie florestal.

\begin{abstract}
We evaluated the development and the nutritional status of Acacia mearnsii De Wild. seedlings produced in four organic substrates with poultry litter base, distributed in percentage terms: T1: 25CA:50S:25A; T2: 50CA25S25A; T3: 25CA75S and T4: 100SC (CA: poultry litter; S: soil; A: sand; SC: commercial substrate), in tubes of $125 \mathrm{~cm}^{3}$ conducted in greenhouse / shade area. The best results, to the morphological variables height, stem diameter, number of leaves, dry mass of roots and total, were obtained in commercial substrate and in between 25 to $50 \%$ of poultry litter with clay soil and sand. The $\mathrm{N}$ and $\mathrm{Mg}$ contents (shoot and roots) and $\mathrm{P}$ and $\mathrm{K}$ (shoot) were not influenced by substrates. In the roots, the $\mathrm{P}$ content was greater on treatment with biggest proportion of clay soil. The $\mathrm{K}$, in the roots, had the highest levels in substrates composed of 25 to $50 \%$ of poultry litter and commercial substrate. For $\mathrm{Ca}$, the contents in shoots were higher than roots, mainly in the substrates with up to $50 \%$ of poultry litter. In the roots, the proportion of poultry litter did not influence $\mathrm{Ca}$. The tested substrates, generally, did not influence the nutritional status of the seedlings.
\end{abstract}

KEYWORDS: alternative substrate, forest nutrition, forest specie.

\section{INTRODUÇÃO}

A produção de mudas florestais tem passado por grandes avanços tecnológicos nos últimos anos, com melhorias que incluíram a seleção de árvores matrizes superiores, propagação vegetativa, uso de embalagens reaproveitáveis ou biodegradáveis, mudanças no manejo dos viveiros e uso de substratos alternativos.

O uso de substratos é parte fundamental na produção de mudas florestais, pois é nesse meio que ocorre o plantio das sementes ou o enraizamento de estacas, ocorrendo a devida sustentação às plantas, com o fornecimento de água, nutrientes e oxigênio ao sistema radicular das mesmas. Nos últimos anos, 
muitas pesquisas sobre a formulação de substratos têm abordado o uso de materiais residuais orgânicos, tanto como forma de otimizar a produção de mudas, como também mitigar possíveis impactos ambientais desses materiais, caso não convenientemente destinados na natureza.

Diversos trabalhos sobre o uso e eficiência de resíduos orgânicos de processos produtivos na elaboração de substratos para a produção de mudas de espécies florestais podem ser citados, tais como: CALDEIRA et al. (2012), com Ateleia glazioveana; COSTA et al. (2011), com Corymbia citriodora; WENDLING et al. (2007), e WENDLING et al. (2006), com Ilex paraguariensis; MAEDA et al. (2007), com substratos orgânicos diversos; CUNHA et al. (2006), com duas espécies de Acacia sp.; DELARMELINA et al. (2015), com Chamaecrista desvauxii var. latistipula; CHAVES et al. (2006), com Anadenanthera macrocarpa; e CHARLO et al. (2006), com Archontophoenix alexandrae, entre outros. Porém, praticamente não existem trabalhos testando a cama de aviário para a produção de mudas de Acacia mearnsii, como no presente estudo.

A cama de aviário é formada por dejetos, penas, resíduos de ração e outros, acumulados sobre o piso das granjas de produção, a qual, devido à forte preocupação ambiental quanto ao destino dado a esse resíduo, para que seu uso seja feito de maneira correta, o tratamento pode ocorrer por compostagem ou biodigestão anaeróbica, com a geração de produtos como o composto orgânico humificado, usado como adubo orgânico (MCGRATH et al. 2009).

Assim, estudar as composições mais adequadas de substratos com uso de cama de aviário torna-se importante, pois dificilmente um material puro conseguirá alcançar todas as características desejáveis de um bom substrato, sendo fundamental a quantificação da matéria orgânica necessária na sua composição.

A cama de aviário tem teores nutricionais superiores aos dejetos de outros animais domésticos, com menor umidade, excrementos sólidos e líquidos misturados, sendo, geralmente, proveniente de aves criadas com rações concentradas. Possui compostos ricos em nitrogênio $(N)$, que auxiliam no aumento da produção de culturas (SERRANO et al. 2011). Os teores de N, P e K, respectivamente, podem alcançar valores elevados, de até $36,5 \mathrm{~g}, 13,3 \mathrm{~g}$ e 33,6 $\mathrm{g} \mathrm{kg}^{-1}$ (VIRTUOSO et al. 2015), assim como altos teores de Cálcio ( $\mathrm{Ca}$ ) e Magnésio ( $\mathrm{Mg}$ ), sendo bastante variáveis conforme a origem da cama (aves de corte ou poedeiras), e do número de camadas de maravalha (fragmentos de madeira usados como cama para as aves), tendo a capacidade de aumentar o pH e diminuir o teor de alumínio trocável no solo.

A cama de aviário é um produto encontrado com facilidade em região com tradição da avicultura. $A$ formulação de substratos geralmente envolve produtos disponíveis em uma região, o que torna o produto mais barato, justificando, desta maneira, o uso deste produto na formulação de substratos, além de, ambientalmente, dar um destino mais adequado para estes dejetos.

O objetivo desse trabalho foi avaliar o desenvolvimento e estado nutricional de mudas de Acacia mearnsii De Wild., produzidas a partir de substratos a base de diferentes proporções de cama de aviário, solo e areia.

\section{MATERIAL E MÉTODOS}

O estudo ocorreu em viveiro florestal, em região de clima Cfa, subtropical de verões quentes, com temperatura média anual de $19{ }^{\circ} \mathrm{C}$ e precipitação entre 1800 e $2000 \mathrm{~mm}$ anuais, bem distribuídos no ano (ALVARES et al. 2013). O experimento foi realizado entre os meses de outubro a janeiro, instalado e conduzido, no primeiro mês, em casa de vegetação, otimizando a emergência das plântulas, seguido de casa de sombra $(50 \%)$ até o final do experimento.

As sementes de acácia-negra usadas na pesquisa foram obtidas na empresa Agroseta S.A. (ButiáRS), com origem em ACS (Área de Coleta de Sementes). O experimento foi instalado em delineamento inteiramente casualizado, utilizando-se quatro tratamentos e quatro repetições (20 mudas cada). Os tratamentos foram compostos das proporções: T1 - 25\% cama de aviário (CA) $+50 \%$ solo $(\mathrm{S})+25 \%$ areia (A); T2 - 50\% CA + 25\% S + 25\% A; T3 - 25\% CA + 75\% S; T4 - 100\% substrato comercial de casca de pinus.

O Latossolo Vermelho distroférrico típico, textura argilosa, usado na composição do substrato foi coletado no horizonte B do perfil, com proporção média de $65 \%$ de argila (argiloso), o qual tem como características principais, em níveis médios, com base em análise realizada em laboratório de solos: $\mathrm{pH}$ de 4,2; matéria orgânica de 18,6 g kg-1; $1,9 \mathrm{~g} \mathrm{~kg}^{-1}$ de N; 3,96 mg kg${ }^{-1}$ de $\mathrm{P} ; 1,27 \mathrm{cmolc} \mathrm{dm}^{-3}$ de $\mathrm{K} ; 6,58 \mathrm{cmol}_{\mathrm{c}}$ $\mathrm{dm}^{-3}$ de Ca; $2,29 \mathrm{cmol}_{\mathrm{c}} \mathrm{dm}^{-3}$ de $\mathrm{Mg}$ e $53,6 \%$ de saturação de bases (V\%). A areia foi adquirida no comércio local, de textura média, tendo sido lavada em água corrente antes de ser incluída na composição dos materiais.

A cama de aviário utilizada foi coletada em três aviários locais, após o uso por cinco lotes de frangos 
e mantida por três meses em pilha de compostagem antes de sua aplicação no substrato. Em níveis médios, apresentou teores de $\mathrm{N}, \mathrm{P}, \mathrm{K}, \mathrm{Ca}$ e $\mathrm{Mg}\left(\mathrm{g} \mathrm{kg}^{-1}\right)$, iguais a 17,5; 11,7; 17,4; 12,3 e 3,5, respectivamente, avaliados com base em três amostras compostas coletadas após a permanência na pilha e analisadas em laboratório. Para todas as combinações dos tratamentos foram realizadas análises, com base em três amostras, de atributos físicos (densidade $-\mathrm{g} \mathrm{cm}^{-3}$ e porosidade total - \%) e químicos: matéria

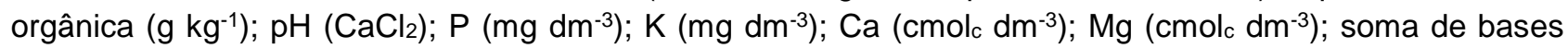
$\left(\mathrm{cmol}_{\mathrm{c}} \mathrm{dm}^{-3}\right) ; \mathrm{V}(\%) ; \mathrm{CTC} \mathrm{Al}\left(\mathrm{cmol}_{\mathrm{c}} \mathrm{dm}^{-3}\right) ; \mathrm{H}+\mathrm{Al}\left(\mathrm{cmol}_{\mathrm{c}} \mathrm{dm}^{-3}\right)$ e saturação de $\mathrm{Al}(\%)$.

Para o estudo, foram utilizados tubetes com volume de $125 \mathrm{~cm}^{3}$, lavados com solução de hipoclorito (10\%) visando eliminar possíveis patógenos. O solo, a areia e a cama de aviário foram peneirados, medidos (volume) e homogeneizados. A adubação adicionada a todos os substratos, de forma padrão, foi de $1 \mathrm{~kg} / \mathrm{m}^{3}$ de NPK 4-14-8, misturada aos substratos e colocada nos tubetes, efetuando sua acomodação para evitar o excesso de ar no substrato e melhorar o desenvolvimento radicular. Essa adubação padrão foi aplicada em função de ser a mesma usual em viveiros da região, de forma que a mesma não influenciasse nos resultados, que visaram, prioritariamente, avaliar o efeito dos substratos com cama de aviário, e não da adubação.

As sementes foram desinfestadas com hipoclorito de sódio a $2 \%$ por 3 minutos antes da semeadura, a qual ocorreu com cinco sementes por tubete onde, após a emergência das plântulas, foram desbastadas, deixando-se a plântula mais vigorosa e centralizada em cada um.

A irrigação foi realizada por aspersão, em dois turnos, entre 9 e 10 horas da manhã e 15 e 16 horas da tarde, por 15 minutos cada turno (vazão de $150 \mathrm{~L} / \mathrm{h}$, espaçados a cada $9 \mathrm{~m}^{2}$ ), dando a disponibilidade hídrica adequada para as mudas, observada in loco em função do bom umedecimento dos substratos de cada tratamento e início de ocorrência de drenagem.

No 110 dia após a emergência das plantas, avaliaram-se a altura total $(H)$ e diâmetro do colo (Dc), e, com isso, foi calculada a relação altura/diâmetro do colo $(\mathrm{H} / \mathrm{Dc})$, sendo também contados o número de folhas das mudas (Nf). Através de seleção por sorteio, seis plantas de cada repetição foram amostradas quanto à massa seca da parte aérea (MSPA) e radicular (MSR), para isso, sendo cortadas ao nível do colo e separadas nas frações parte aérea e sistema radicular, tendo essa última sido lavada com jato d'água sobre peneira fina (<1 mm de malha), visando à completa separação do substrato aderido a mesma. As frações foram postas a secar em estufa de circulação e renovação de ar a $65{ }^{\circ} \mathrm{C}$ por 72 horas, sendo pesadas em balança de precisão $(0,01 \mathrm{~g})$, obtendo-se então, a MSPA e MSR, cuja soma forneceu a massa seca total (MST).

O Índice de Qualidade de Dickson (IQD) foi determinado pela fórmula: IQD = MST / $(H / D c+$ MSPA/MSR).

As seis plantas de cada repetição foram reunidas em uma única amostra e moídas para a determinação, conforme metodologia padrão do laboratório de análise de solos da Universidade Tecnológica Federal do Paraná, quanto aos teores de N (Kjeldahl), P (Espectrofotômetro UV-VIS), K (Fotômetro de chama), Ca e Mg (Espectrofotometria de absorção atômica).

Todos os dados obtidos foram analisados quanto à variância e às médias comparadas pelo teste de Duncan a $5 \%$ de probabilidade de erro, por meio do software Statistical Package for the Social Sciences (SPSS v. 8.0).

\section{RESULTADOS}

Em relação aos atributos físicos, os substratos apresentaram densidade $\left(\mathrm{g} \mathrm{cm}^{-3}\right)$ de 0,49;0,39;0,71 e 0,33; e porosidade total (\%) de 59; 69; 42 e 79, respectivamente, para os tratamentos 1 até 4 (T1 - 25\% cama de aviário (CA) $+50 \%$ solo $(S)+25 \%$ areia $(A) ;$ T2 $-50 \% C A+25 \% S+25 \%$ A; T3 $-25 \%$ CA + $75 \%$ S; T4 - 100\% substrato comercial de casca de pinus). Já os resultados da análise química mostraram grande amplitude entre os tratamentos, conforme Tabela 1.

O teor de matéria orgânica nos tratamentos T2 e T4 foram considerados altos, sendo médio no T3 e baixo no T1 (CQFS-RS/SC 2004). O pH dos substratos se mostrou elevado, com valores estatisticamente superiores para os três tratamentos à base de cama de aviário, estando ambos acima de seis, ao contrário do substrato comercial, que apresentou um valor muito baixo, fato que pode acarretar problemas de desenvolvimento às plantas, em função de restrições químicas à absorção de alguns nutrientes, como, por exemplo, o fósforo, uma vez que o mesmo é essencial para o crescimento, desenvolvimento e reprodução das plantas (EPSTEIN \& BLOOM 2006), mesmo com os teores de P tendo sido considerados altos para todos os tratamentos, não diferindo estatisticamente entre eles.

Os teores de $\mathrm{K}$, considerados altos para todos os tratamentos, foram ainda estatisticamente 
superiores no substrato, com $50 \%$ de cama de aviário (T2), em comparação aos que possuem $25 \%$ (T1 e T3) e no comercial (T4). Os teores de Ca e Mg também foram considerados de médios a altos para todos os tratamentos, sobressaindo-se, no caso do Ca, no substrato comercial (T4) e também no T2, com $50 \%$ de cama de aviário, no caso do Mg.

Tabela 1. Atributos químicos dos substratos usados no experimento de diferentes substratos no crescimento de mudas de Acacia mearnsii.

Table 1. Chemical attributes of the substrates used in the experiment with different substrates in the growth of Acacia mearnsii seedlings.

\begin{tabular}{|c|c|c|c|c|}
\hline Variável & T1 & T2 & T3 & T4 \\
\hline Matéria orgânica $\left(\mathrm{g} \mathrm{kg}^{-1}\right)$ & $18,0 b^{*}$ & $95,0 \mathrm{a}$ & $29,0 \mathrm{~b}$ & $89,0 \mathrm{a}$ \\
\hline $\mathrm{pH}\left(\mathrm{CaCl}_{2}\right)$ & $6,3 \mathrm{~b}$ & $7,3 \mathrm{a}$ & $6,4 \mathrm{~b}$ & $3,9 \mathrm{c}$ \\
\hline $\mathrm{P}\left(\mathrm{mg} \mathrm{dm}^{-3}\right)$ & $94,2^{\text {ns }}$ & 101,2 & 90,6 & 94,2 \\
\hline $\mathrm{K}\left(\mathrm{mg} \mathrm{dm^{-3 } )}\right.$ & $2,6 \mathrm{~b}$ & $12,0 \mathrm{a}$ & $3,3 \mathrm{~b}$ & $1,5 \mathrm{c}$ \\
\hline $\mathrm{Ca}\left(\mathrm{cmol}_{\mathrm{c}} \mathrm{dm}^{-3}\right)$ & $3,6 \mathrm{~b}$ & $3,6 \mathrm{~b}$ & $3,2 \mathrm{~b}$ & $12,4 \mathrm{a}$ \\
\hline $\mathrm{Mg}\left(\mathrm{cmol}_{\mathrm{c}} \mathrm{dm}^{-3}\right)$ & $0,8 \mathrm{c}$ & $4,2 \mathrm{a}$ & $2,5 \mathrm{~b}$ & $4,9 \mathrm{a}$ \\
\hline Soma de Bases $\left(\mathrm{cmol}_{\mathrm{c}} \mathrm{dm}^{-3}\right)$ & $7,0 \mathrm{~b}$ & $19,8 \mathrm{a}$ & $9,1 \mathrm{~b}$ & $18,8 \mathrm{a}$ \\
\hline $\mathrm{V}(\%)$ & $67,2 \mathrm{~b}$ & $88,9 a$ & $72,6 \mathrm{ab}$ & $45,6 \mathrm{c}$ \\
\hline CTC & $10,4 \mathrm{c}$ & $22,3 \mathrm{~b}$ & $12,5 \mathrm{c}$ & $41,2 \mathrm{a}$ \\
\hline $\mathrm{Al}\left(\mathrm{cmol}_{\mathrm{c}} \mathrm{dm}^{-3}\right)$ & $0,0^{* *}$ & 0,0 & 0,0 & 0,9 \\
\hline $\mathrm{H}+\mathrm{Al}\left(\mathrm{cmol}_{\mathrm{c}} \mathrm{dm}^{-3}\right)$ & $3,4 \mathrm{~b}$ & $2,5 \mathrm{~b}$ & $3,4 \mathrm{~b}$ & $22,5 \mathrm{a}$ \\
\hline Saturação de Al (\%) & $0,0^{* *}$ & 0,0 & 0,0 & 4,3 \\
\hline
\end{tabular}

Onde: T1: substrato formado por $25 \%$ cama de aviário, $50 \%$ solo e $25 \%$ areia; T2: $50 \%$ cama de aviário, $25 \%$ solo e 25\% areia; T3: $25 \%$ cama de aviário e $75 \%$ solo; T4: $100 \%$ substrato comercial de casca de pinus.

* médias de três repetições, seguidas pela mesma letra, na horizontal, não diferem entre si pelo teste de Duncan a $5 \%$ de probabilidade de erro; ** teste não realizado; ns: não significativo.

A soma de bases foi superior no T2 e T4, em comparação com os demais tratamentos, mesmo comportamento apresentado pela CTC. A saturação de bases foi superior nos tratamentos T2 e T3. Nessa variável, o substrato comercial (T4) apresentou o menor valor. Os teores de Al e sua saturação foram considerados baixos, menos no T4, com valores elevados.

Em relação às variáveis de crescimento $\mathrm{Nf}$, Dc e H (Tabela 2), pode-se observar que o T4 se destacou para todas. Entretanto, o T1, sendo um substrato alternativo com $25 \%$ de cama de aviário, não apresentou diferença significativa em relação ao mesmo. Para Dc, o T2 também não apresentou diferença estatística em relação aos melhores tratamentos encontrados. O T3 apresentou os piores resultados para as três variáveis analisadas, com grande variabilidade de médias em relação aos demais tratamentos.

Os melhores tratamentos quanto a MSR, MSPA e MST foram nos substratos T4, T2 e T1, mostrando que a presença de maior proporção de solo argiloso no substrato (T3) causa problemas ao crescimento das mudas, com média inferior aos demais tratamentos (Tabela 3).

A relação entre os parâmetros morfológicos se apresentou de maneira diferenciada nos substratos (Tabela 4). A relação H/Dc no T1 esteve na faixa considerada adequada $(5,4$ a 8,1$)$, ocorrendo valor superior a 8,1 para o T4 $(10,06)$ e T2 $(8,33)$, e inferior a 5,4 para o substrato T3 $(4,77)$.

Na relação H/MSPA, quanto menor o quociente da divisão, melhor a qualidade da muda. Nesse caso, o substrato que apresentou a melhor relação foi o composto por $25 \%$ de cama de aviário e $75 \%$ de solo (T3) $(2,48)$, o qual, porém, apresentou também as menores médias para todos os demais parâmetros morfológicos avaliados, sendo importante ressaltar a análise conjunta de todas as variáveis de forma a indicar o melhor tratamento.

Tabela 2. Variáveis morfológicas das mudas de Acacia mearnsii 110 dias após a emergência. Table 2. Morphological variables of Acacia mearnsii seedlings, 110 days after emergence.

\begin{tabular}{|c|c|c|c|}
\hline Tratamentos & Número de folhas (Nf) & $\begin{array}{c}\text { Diâmetro do colo (Dc) } \\
(\mathrm{mm})\end{array}$ & Altura da parte aérea $(\mathrm{H})(\mathrm{cm})$ \\
\hline $\bar{T} 1^{*}$ & $70,8 \mathrm{a}^{\star *}$ & $3,17 \mathrm{a}$ & $25,6 \mathrm{ab}$ \\
\hline T2 & $45,9 \mathrm{~b}$ & $2,70 \mathrm{a}$ & $22,5 b$ \\
\hline T3 & $12,2 \mathrm{c}$ & $1,36 \mathrm{~b}$ & $6,5 \mathrm{c}$ \\
\hline T4 & $71,7 \mathrm{a}$ & $2,96 \mathrm{a}$ & $29,8 \mathrm{a}$ \\
\hline MÉDIA & 52,7 & 2,5 & 21,1 \\
\hline CV (\%) & 49,4 & 31,3 & 45,0 \\
\hline
\end{tabular}

* Onde: T1: substrato formado por $25 \%$ cama de aviário, $50 \%$ solo e $25 \%$ areia; T2: $50 \%$ cama de aviário, $25 \%$ solo e $25 \%$ areia; T3: $25 \%$ cama de aviário e $75 \%$ solo; T4: $100 \%$ substrato comercial de casca de pinus. ${ }^{* *}$ médias seguidas pela mesma letra, na vertical, não diferem entre si pelo teste de Duncan, a $5 \%$ de probabilidade de erro. 
Tabela 3. Massa seca (g) das mudas de Acacia mearnsii aos 110 dias após a emergência. Table 3. Dry mass (g) of the seedlings of Acacia mearnsii at the 110 days after emergence.

\begin{tabular}{lccc}
\hline Tratamentos & MSR (g/planta) & MSPA (g/planta) & MST (g/planta) \\
\hline T1* & $0,56 \mathrm{a}^{* *}$ & $3,71 \mathrm{a}$ & $4,27 \mathrm{a}$ \\
T2 & $0,59 \mathrm{a}$ & $3,74 \mathrm{a}$ & $4,32 \mathrm{a}$ \\
T3 & $0,10 \mathrm{~b}$ & $2,62 \mathrm{~b}$ & $2,72 \mathrm{~b}$ \\
T4 & $0,88 \mathrm{a}$ & $3,45 \mathrm{a}$ & $4,32 \mathrm{a}$ \\
\hline Média & 0,56 & 3,38 & 3,93 \\
CV $(\%)$ & 61,5 & 25,4 & 28,3 \\
\hline
\end{tabular}

* Onde: T1: substrato formado por $25 \%$ cama de aviário, $50 \%$ solo e $25 \%$ areia; T2: $50 \%$ cama de aviário, $25 \%$ solo e 25\% areia; T3: 25\% cama de aviário e $75 \%$ solo; T4: 100\% substrato comercial de casca de pinus.

** médias seguidas pela mesma letra, na vertical, não diferem entre si pelo teste de Duncan a $10 \%$ de probabilidade de erro.

Tabela 4. Índices de qualidade de mudas de Acacia mearnsii aos 110 dias após a emergência.

Table 4. Quality index of the seedlings of Acacia mearnsii at the 110 days after emergence.

\begin{tabular}{lcccc}
\hline \multicolumn{1}{c}{ Tratamentos } & $\mathrm{H} / \mathrm{Dc}^{*}$ & $\mathrm{H} / \mathrm{MSPA}$ & $\mathrm{MSPA} / \mathrm{MSR}$ & $\mathrm{IQD}$ \\
\hline T1* & $8,07 \mathrm{~b}^{* *}$ & $6,94 \mathrm{~b}$ & $6,62 \mathrm{~b}$ & $0,29 \mathrm{a}$ \\
T2 & $8,33 \mathrm{~b}$ & $6,01 \mathrm{~b}$ & $6,33 \mathrm{~b}$ & $0,29 \mathrm{a}$ \\
T3 & $4,77 \mathrm{c}$ & $2,48 \mathrm{c}$ & $26,2 \mathrm{a}$ & $0,08 \mathrm{~b}$ \\
T4 & $10,06 \mathrm{a}$ & $8,63 \mathrm{a}$ & $3,92 \mathrm{c}$ & $0,30 \mathrm{a}$ \\
\hline MÉDIA & 7,81 & 6,00 & 10,77 & 0,24 \\
CV (\%) & 10,7 & 52,5 & 20,9 & 32,8 \\
\hline
\end{tabular}

${ }^{*}$ Onde: T1: substrato formado por $25 \%$ cama de aviário, $50 \%$ solo e $25 \%$ areia; T2: $50 \%$ cama de aviário, $25 \%$ solo e 25\% areia; T3: 25\% cama de aviário e 75\% solo; T4: 100\% substrato comercial de casca de pinus; H/Dc: relação altura da parte aérea com o Diâmetro do colo; H/MSPA: relação altura da parte aérea e massa seca da parte aérea; MSPA/MSR: relação massa seca da parte aérea com a massa seca de raízes; IQD: índice de qualidade de Dickson;

${ }^{* *}$ médias seguidas pela mesma letra, na vertical, não diferem entre si pelo teste de Duncan a $5 \%$ de probabilidade de erro.

A relação que combina os parâmetros MSPA e MSR deve ter valores próximos de 2,0, o qual ocorreu, de forma mais próxima, no substrato T4 $(3,92)$ (Tabela 4).

O IQD é um parâmetro muito utilizado para determinar a qualidade das mudas, o valor mínimo deve ser 0,20 (MARQUES et al. 2006). O T3 não alcançou esse limite mínimo. O maior valor encontrado foi para o substrato T4, que pouco se diferenciou dos tratamentos T1 e T2, os quais apresentaram o mesmo índice de qualidade para as mudas.

Conforme a Tabela 5, embora os níveis de $\mathrm{N}$ tenham apresentado um valor absoluto superior no T3, não houve diferença estatística entre os tratamentos, indicando que as concentrações de $\mathrm{N}$, tanto na parte aérea como nas raízes, não foram influenciadas pelos tratamentos. Apesar dos teores de matéria orgânica dos substratos serem mais elevados nos tratamentos com a presença de $50 \%$ de cama de aviário e no substrato comercial, foram estes justamente os tratamentos onde ocorreram os menores teores de $\mathrm{N}$ nas duas frações, em termos absolutos.

Para o $\mathrm{P}$ na parte aérea, não houve diferença significativa entre os tratamentos, fato correspondente aos teores igualmente semelhantes nos diferentes substratos. No caso do K, o maior teor no substrato com $50 \%$ de cama de aviário (T2), influenciou na parte aérea das mudas, também com teor elevado, apesar da parte aérea das mudas dos demais substratos também terem apresentado alto teor do nutriente, não os diferenciando estatisticamente. Para as raízes, T1 e T2 apresentam maiores teores, não diferindo do T4. O T3 apresentou menor teor, não diferindo do T4. Para o teor de P no sistema radicular, o T3 apresentou maior teor, com os demais não diferindo entre si.

Para o $\mathrm{Ca}$, os maiores teores ocorreram no $\mathrm{T} 1$ e T2, os quais, apesar de terem apresentado teores menores do que o T4, mostraram boas condições de absorção desse nutriente e fixação na parte aérea (Tabela 5). Nas raízes, não ocorreram diferenças entre os teores. O Mg, apesar dos maiores teores no T2 e T4, não mostrou essa correspondência nos teores presentes na parte aérea e nas raízes das mudas, com todos os teores não se diferenciando entre si.

\section{DISCUSSÃO}

A influência dos tratamentos testados no desenvolvimento das mudas de acácia-negra, nas variáveis $\mathrm{H}$, Dc e Nf, mostrou que o uso de $25 \%$ de cama de aviário em mistura com solo e areia tem a mesma eficiência que o substrato comercial na produção de mudas para a espécie em estudo. O fato do Dc não se 
diferenciar estatisticamente quando do uso de $50 \%$ desse material aponta para a possibilidade de que proporções maiores possam também ser misturadas, desde que outras características do substrato sejam satisfeitas, como na questão física, com proporção de solo argiloso não passando de $50 \%$ e tendo pelo menos $25 \%$ de areia, de forma a dar maior permeabilidade ao substrato, com menor densidade e mais porosidade.

$\mathrm{O}$ pH mais elevado no T2 é diretamente relacionado à maior proporção de cama de aviário nesse substrato, fato que também se tornou prejudicial ao desenvolvimento das mudas, pois, mesmo com teores elevados de nutrientes, a absorção é prejudicada por valores maiores que sete desse índice que, segundo FERNANDES \& SOUZA (2006), podem, nesses casos, diminuir a disponibilidade de nutrientes como $\mathrm{Ca}$, $\mathrm{Mg}$, alguns micronutrientes e, até mesmo, de $\mathrm{P}$.

Ao que tudo indica, para espécies rústicas e de rápido crescimento, como a Acácia-negra, a absorção de nutrientes e o crescimento das plantas ocorrem de maneira mais adequada quando cultivadas em substratos com pH mais ácido (como o substrato comercial) do que naqueles com valor mais elevado, com certa alcalinidade.

A relação entre qualidade do substrato e crescimento das mudas, para o caso do presente estudo, mostra que a influência do primeiro fator sobre o segundo é limitada principalmente pelo $\mathrm{pH}, \mathrm{o}$ qual influencia diretamente na capacidade de absorção de nutrientes, e pela condição física do material, em que os substratos com menor densidade e maior porosidade tenderam a ser mais adequados no desenvolvimento das mudas.

WENDLING et al. (2006) mencionam que materiais de origem orgânica permitem o desenvolvimento de organismos benéficos para as plantas, aumentando a disponibilidade de nutrientes ao longo do tempo da produção de mudas, como também o pH e a capacidade de troca catiônica, porém, essas alterações vão depender diretamente da qualidade e quantidade do composto utilizado. A cama de aviário, mesmo sendo fonte de matéria orgânica e nutrientes para substratos, pode ter influência variável nas suas condições físicas e químicas, afetando o desenvolvimento das mudas, devendo ter seu processo de compostagem realizado de forma completa para que seja mais eficiente no condicionamento físico e químico dos substratos nos quais for adicionada.

SEVERINO et al. (2006), estudando os teores nutricionais de 11 materiais orgânicos, encontraram valores de $\mathrm{P}, \mathrm{K}, \mathrm{Ca}$ e $\mathrm{Mg}$ mais altos em cama de aviário em comparação com bagaço de cana, casca de amendoim, casca de mamona, cinza de madeira, esterco bovino, mucilagem de sisal, polpa de mamona, tegumento de mamona, torta de algodão e torta de mamona, ressaltando que nenhum dos materiais orgânicos é completo, recomendando-se a associação com outros, de forma que se complementem, tanto física quanto quimicamente. Isso demonstra que as misturas realizadas para o presente estudo, nos tratamentos com melhores resultados, foram eficientes na disponibilização de água e nutrientes para as plantas.

Dados similares aos obtidos no presente estudo foram alcançados por CUNHA et al. (2006), testando formulações de substratos orgânicos na produção de mudas de Acacia mangium e A. auriculiformis, cujos melhores materiais foram o solo com esterco bovino e lodo de esgoto, quanto ao diâmetro do colo, altura da parte aérea, massa seca de raízes e de parte aérea.

Tabela 5. Teores nutricionais $\left(\mathrm{g} \mathrm{kg}^{-1}\right)$ na parte aérea e raízes de Acacia mearnsii nos tratamentos.

Table 5. Nutrient content $\left(\mathrm{g} \mathrm{kg}^{-1}\right)$ in the shoot and roots of Acacia mearnsii in the treatments.

\begin{tabular}{|c|c|c|c|c|c|c|}
\hline \multirow[b]{2}{*}{ Tratamentos } & \multirow{2}{*}{ Fração } & $\mathrm{N}$ & $P$ & $\mathrm{~K}$ & $\mathrm{Ca}$ & $\mathrm{Mg}$ \\
\hline & & \multicolumn{5}{|c|}{ - Teor $\left(\mathrm{g} \mathrm{kg}^{-1}\right)$} \\
\hline \multirow{2}{*}{$\mathrm{T} 1^{*}$} & Parte aérea & $10,0 \mathrm{a}^{\star *}$ & $18,2 \mathrm{a}$ & $21,4 a$ & $11,2 \mathrm{a}$ & $2,9 \mathrm{a}$ \\
\hline & Raízes & $20,0 \mathrm{~A}$ & $13,1 \mathrm{~B}$ & $19,5 \mathrm{~A}$ & $3,0 \mathrm{~A}$ & 4,4 A \\
\hline \multirow[b]{2}{*}{ T2 } & Parte aérea & $8,8 \mathrm{a}$ & $14,9 \mathrm{a}$ & $16,9 a$ & $10,2 \mathrm{a}$ & $3,2 a$ \\
\hline & Raízes & $17,5 \mathrm{~A}$ & $13,3 \mathrm{~B}$ & $18,3 \mathrm{~A}$ & 2,3 A & $4,8 \mathrm{~A}$ \\
\hline \multirow{2}{*}{ T3 } & Parte aérea & $17,4 \mathrm{a}$ & $19,9 \mathrm{a}$ & $18,9 \mathrm{a}$ & $6,6 \mathrm{~b}$ & $4,5 \mathrm{a}$ \\
\hline & Raízes & $20,2 \mathrm{~A}$ & $21,0 \mathrm{~A}$ & $6,8 \mathrm{~B}$ & $3,2 \mathrm{~A}$ & $6,1 \mathrm{~A}$ \\
\hline \multirow{2}{*}{ T4 } & Parte aérea & $10,8 \mathrm{a}$ & $15,5 \mathrm{a}$ & $20,1 \mathrm{a}$ & $4,4 \mathrm{~b}$ & $3,2 \mathrm{a}$ \\
\hline & Raízes & $19,0 \mathrm{~A}$ & $10,9 \mathrm{~B}$ & $16,0 \mathrm{AB}$ & $1,6 \mathrm{~A}$ & $3,2 \mathrm{~A}$ \\
\hline
\end{tabular}

${ }^{*}$ Onde: T1: substrato formado por $25 \%$ cama de aviário, $50 \%$ solo e $25 \%$ areia; T2: $50 \%$ cama de aviário, $25 \%$ solo e $25 \%$ areia; T3: $25 \%$ cama de aviário e $75 \%$ solo; T4: $100 \%$ substrato comercial de casca de pinus.

${ }^{* *}$ médias seguidas pela mesma letra, na vertical, minúsculas para parte aérea e maiúsculas para raízes, não diferem entre si pelo teste de Duncan a $5 \%$ de probabilidade de erro. 
WENDLING et al. (2006) relataram que os melhores substratos para mudas de llex paraguariensis, com base no diâmetro do colo e altura, são os compostos por mais de $70 \%$ de substrato comercial a base de casca de pinus ou, compensatoriamente, com a presença de esterco bovino (mínimo de 30\%), mostrando que os materiais orgânicos compensam a menor proporção de substratos comerciais e, inclusive, de materiais com conhecida baixa capacidade de retenção de nutrientes, como a serragem semidecomposta e palitos de erva-mate. Esses resultados mostram comportamento similar ao presente estudo, no qual a cama de aviário consegue substituir o substrato comercial com o mesmo êxito, se usada em proporções adequadas.

O T3 apresentou os piores resultados para a H, Dc e Nf, fato associado à compactação do substrato ocorrida no recipiente, pela proporção elevada de solo argiloso de maior densidade, consequentemente, causando baixa aeração e diminuição da infiltração de água, pela menor porosidade, comprometendo o desenvolvimento radicular das plantas e causando redução do seu crescimento.

O uso de até $50 \%$ de cama de aviário na composição de substratos pode ser recomendado para a produção de mudas de acácia-negra, proporcionando as mesmas características semelhantes às produzidas em substrato comercial, com base nas variáveis morfológicas avaliadas, tendo a cama de aviário efeito similar a outros materiais residuais, como esterco bovino, testado por COSTA et al. (2011) com Corymbia citriodora, WENDLING et al. (2007) e WENDLING et al. (2006) com Ilex paraguariensis, CUNHA et al. (2006) com duas espécies de Acacia sp. e CHARLO et al. (2006) com Archontophoenix alexandrae.

A altura da parte aérea da planta, combinada com o respectivo diâmetro do colo, constitui um dos mais importantes parâmetros para estimar o crescimento das mudas após o plantio definitivo em campo. Essa relação $\mathrm{H} / \mathrm{Dc}$ é ideal quando se situa na faixa entre 5,4 a 8,1. No presente estudo, os tratamentos com $25 \%$ e $50 \%$ de cama de aviário apresentaram valores dentro desse intervalo (Tabela 4).

Para MARQUES et al. (2006), quanto menor o quociente obtido pela divisão da altura da parte aérea pela massa seca da parte aérea, mais lignificada será a muda e maior o seu potencial de sobrevivência a campo. Porém, autores como SILVA et al. (2012) afirmam que os parâmetros morfológicos e suas relações não devem ser utilizados isoladamente para a classificação do padrão de qualidade, devido à possibilidade de selecionar mudas altas, porém fracas, descartando as menores, mas com maior vigor.

Em relação à combinação entre os parâmetros MSPA e MSR, trabalhos como ROSSA et al. (2015) relatam que a melhor relação entre os mesmos deve ser em torno de 2,0. O tratamento T3, em função da sua pequena MSR, apresentou a maior relação (Tabela 4), fato que se justifica devido aos impedimentos físicos ao crescimento das mesmas nessa situação. Essa razão é comumente maior em ambiente de baixa fertilidade, podendo ser uma estratégia da planta para extrair o máximo de nutrientes naquela condição.

Quanto ao IQD, MARQUES et al. (2006) afirmam que quanto maior o seu valor, melhor a qualidade das mudas, sendo que o valor mínimo deve ser 0,20 . Esse fato ocorreu com os três melhores tratamentos do estudo $(0,29$ a 0,30$)$, excetuando-se aquele com $75 \%$ de solo argiloso (T3) em sua composição, que ficou bem aquém $(0,08)$.

Em relação ao status nutricional das mudas, o maior valor absoluto de $\mathrm{N}$, no tratamento 3, pode ter ocorrido por um possível efeito de concentração desse nutriente na parte aérea, à medida que a produção de massa seca foi menor, considerando a capacidade da espécie, como Fabaceae, de fixar $\mathrm{N}_{2}$ atmosférico. Os teores de $\mathrm{N}$ na parte aérea dos demais tratamentos mostraram, por outro lado, que a espécie também apresenta uma boa eficiência de utilização de N, com crescimento maior, mesmo em substratos com menor teor de matéria orgânica. Em termos gerais de comparação, na média entre parte aérea e raízes, os teores

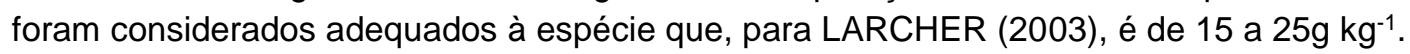

Apesar de todos os substratos usados apresentarem teores de $\mathrm{P}$ semelhantes entre si e elevados (Tabela 1), a faixa ideal de pH do substrato para a absorção (6,5) (FERNANDES \& SOUZA 2006), por parte das raízes, ocorreu, principalmente, no T1 e T3, mesmo que no primeiro tratamento, para as raízes, o teor tenha sido menor. FERNANDES et al. (2000), estudando o crescimento inicial de Schinus terebinthifolious, Chorisia speciosa e Syzygium jambolanum, sob diferentes níveis de fósforo e frações fosfatadas, ressaltam que o fornecimento de $\mathrm{P}$ ao solo ocasionou aumento nos teores de $\mathrm{P}$ nas folhas de todas as espécies estudadas, principalmente nas doses de 300 e $600 \mathrm{mg} \mathrm{dm}^{-3}$.

O K exerce importantes funções reguladoras, participando na ativação de enzimas e na fotossíntese em vários níveis (EPSTEIN \& BLOOM 2006). Por ser altamente móvel, pode ser facilmente perdido ao longo do perfil do solo. Solos ou substratos com maiores teores de Ca e Mg e CTC elevada tendem a diminuir a disponibilidade de $\mathrm{K}$, fato que é nítido nesse estudo (Tabela 5), mostrando a influência da qualidade da cama de aviário no fornecimento de $\mathrm{K}$ e a baixa capacidade do solo para tal, influenciado pela alta CTC do 100SC. 
Em espécies florestais, como as dos gêneros Eucalyptus, Pinus e Araucaria, as faixas de suficiência de $\mathrm{K}$ ficam entre 6 e $15 \mathrm{~g} \mathrm{~kg}^{-1}$ (CQFS-RS/SC 2004), estando todos os tratamentos com teores dentro ou acima do intervalo (Tabela 5), assim como EPSTEIN \& BLOOM (2006), que apresentam um teor referência de $10 \mathrm{~g} \mathrm{~kg}^{-1}$ de $\mathrm{K}$ na massa seca de plantas, em que apenas o T3, nas raízes, apresentou valor inferior. Os teores de $\mathrm{K}$ no tecido vegetal da parte aérea e sistema radicular da espécie estudada no presente experimento estão acima dos valores relatados como ideais pelos autores citados.

EPSTEIN \& BLOOM (2006) relatam um valor referência de $5 \mathrm{~g} \mathrm{~kg}^{-1}$ para o teor de Ca na massa seca de plantas. Para clones de Eucalyptus sp., ROSIM et al. (2016) mostram teores de Ca variando entre 7 e $9 \mathrm{~g} \mathrm{~kg}^{-1}$ (folhas), 3 e $5 \mathrm{~g} \mathrm{~kg}^{-1}$ (galhos), 0,8 e $1,3 \mathrm{~g} \mathrm{~kg}^{-1}$ (madeira) e 12 e $19 \mathrm{~g} \mathrm{~kg}^{-1}$ (casca), sendo considerados como em faixa adequada de ocorrência. No presente estudo, somente o teor nas raízes das mudas no T2 e T4 apresentaram-se menores. Sendo assim, pode-se ressaltar que as mudas de Acacia mearnsii apresentaram teores, na maioria, próximos aos adequados para o seu bom crescimento, não sendo o teor de Ca fator impeditivo para tal.

Para Mg, EPSTEIN \& BLOOM (2006) relatam 2,0 $\mathrm{g} \mathrm{kg}^{-1}$ como teor referência na massa seca de plantas, assim como os valores de referência da CQFS-RS/SC (2004), para espécies florestais, variando entre 2 e $8 \mathrm{~g} \mathrm{~kg}^{-1}$. Dentro desses parâmetros, pode-se destacar que os substratos estudados se mostraram capazes de suprir as necessidades de $\mathrm{Mg}$ das mudas da espécie.

O uso de cama de aviário na produção de mudas de Acacia mearnsii demonstrou plena capacidade de fornecer nutrientes para as plantas, salvo em situações nas quais características físicas dos materiais podem ter impedido a plenitude do processo, tais como, com a presença de proporções elevadas de solo argiloso. Também cabe citar o estudo de PINHO et al. (2006), que avaliaram o estado nutricional da Acacia mearnsii cultivada em solo acrescido de fertilizantes orgânicos, observando que a aplicação de vermicompostos de esterco de suíno e de borra de café, bem como de esterco de aves e o composto Ecocitrus $^{\circledR}$, que proporcionaram um crescimento semelhante ao proporcionado pela adubação química com $\mathrm{N}, \mathrm{P}$ e K.

Os raros estudos existentes quanto às necessidades nutricionais da espécie demonstram pouca resposta à adubação com K, as quais são significativas para N e P. SCHUMACHER et al. (2013), em experimento de campo com a espécie, aos seis anos de idade, relataram que as doses de $40 \mathrm{~kg} \mathrm{ha}^{-1} \mathrm{de} \mathrm{N} \mathrm{e}$ $78,9 \mathrm{~kg} \mathrm{ha}^{-1}$ de $\mathrm{P}$ foram as melhores para o crescimento da espécie.

\section{CONCLUSÃO}

O desenvolvimento de mudas de Acacia mearnsii, com base em variáveis morfológicas e índices de qualidade, é superior com misturas de até $50 \%$ de cama de aviário, juntamente com solo argiloso e areia, comparável ao substrato comercial.

Proporções elevadas de solo argiloso não são recomendadas para produção de mudas de Acacia mearnsii.

Em termos gerais, os teores nutricionais das mudas apresentaram-se pouco influenciados pelos tratamentos, não havendo uma correspondência direta entre teores e crescimento.

\section{REFERÊNCIAS}

ALVARES CA et al. 2013. Köppen's climate classification map for Brazil. Meteorologische Zeitschrift 22: 711-728.

CALDEIRA MVW et al. 2012. Diferentes proporções de biossólido na composição de substratos para a produção de mudas de timbó (Ateleia glazioveana Baill). Scientia Forestalis 93: 15-22.

CHARLO $\mathrm{HCO}$ et al. 2006. Aspectos morfológicos, germinação e desenvolvimento inicial de plântulas de Archontophoenix alexandrae (F. Mueller) H. Wendl. e Drude (Arecaceae) em diferentes substratos. Revista Árvore 30 : 933-940.

CHAVES LLB et al. 2006. Crescimento de mudas de Anadenanthera macrocarpa (Benth) Brenan (Angico-vermelho) em substrato fertilizado e inoculado com rizóbio. Revista Árvore 30: 911-919.

COSTA FG et al. 2011. Esterco bovino para o desenvolvimento inicial de plantas provenientes de quatro matrizes de Corymbia citriodora. Scientia Forestalis 39: 161-169.

CQFS-RS/SC. 2004. Comissão de Química e Fertilidade do Solo. Manual de adubação e calagem para os Estados do Rio Grande do Sul e Santa Catarina. 10.ed. Porto Alegre: Sociedade Brasileira de Ciência do Solo. 400p.

CUNHA AM et al. 2006. Efeito de diferentes substratos sobre o desenvolvimento de mudas de Acacia sp. Revista Árvore 30: 207-214.

DELARMELINA WM et al. 2015. Uso de resíduo orgânico em substrato para produção de Chamaecrista desvauxii (Collad.) Killip var. latistipula (Benth.). Cerne 21: 429-437.

EPSTEIN E \& BLOOM AJ. 2006. Nutrição mineral de plantas: princípios e perspectivas. Tradução: Maria Edna Tenório Nunes. 2.ed. Londrina: Planta. 403p. 
FERNANDES LA et al. 2000. Crescimento inicial, níveis críticos de fósforo e frações fosfatadas em espécies florestais. Pesquisa Agropecuária Brasileira 35: 1191-1198.

FERNANDES MS \& SOUZA SR. 2006. Absorção de nutrientes. In: FERNANDES MS. Nutrição mineral de plantas. Viçosa: SBCS. p.115-152.

LARCHER W 2003. Physiological Plant Ecology: Ecophysiology and Stress Physiology of functional. 3.ed. Berlin: Springer Verlag. 517p.

MAEDA S et al. 2007. Caracterização de substratos para produção de mudas de espécies florestais elaborados a partir de resíduos orgânicos. Pesquisa Florestal Brasileira 54: 97-104.

MARQUES VB et al. 2006. Efeito de fontes e doses de nitrogênio sobre o crescimento inicial e qualidade de mudas de jacarandá-da-bahia (Dalbergia nigra (Vell.) Fr. All. ex Benth.). Revista Árvore 30: 725-735.

MCGRATH S et al. 2009. Improving soil nutrition with poultry litter application in low input forage systems. Agronomy Journal 102: 48-54.

PINHO CF et al. 2006. Estado nutricional da Acácia negra cultivada em solo acrescido de fertilizantes orgânicos. In: XV Congresso de Iniciação Científica / VII Encontro de Pós-Graduação. Anais...Pelotas: UFPEL. p. 45-49.

ROSSA UB et al. 2015. Fertilizante de liberação lenta no desenvolvimento de mudas de Anadenanthera peregrina (L.) Speg. (angico-vermelho) e Schinus terebinthifolius Raddi (aroeira-vermelha). Ciência Florestal 25: 841-852.

ROSIM CC et al. 2016. Nutrient use efficiency in interspecific hybrids of eucalypt. Revista Ciência Agronômica 47: 540547.

SCHUMACHER MV et al. 2013. Crescimento da Acácia-negra em resposta à aplicação de nitrogênio, fósforo e potássio. Cerne 19: 51-58.

SERRANO LAL et al. 2011. Uso de compostos orgânicos no plantio do cafeeiro conilon. Revista Ceres 58: $100-107$.

SEVERINO LS et al. 2006. Composição química de onze materiais orgânicos utilizados em substratos para produção de mudas. Campina Grande: Embrapa Algodão. 5p. (Comunicado Técnico, 278).

SILVA RBG et al. 2012. Qualidade de mudas clonais de Eucalyptus urophylla x E. grandis em função do substrato. Revista Brasileira de Engenharia Agrícola e Ambiental 16: 297-302.

VIRTUOSO MCS et al. 2015. Reutilização da cama de aviário. Revista Eletrônica Nutritime 12: 3964-3979.

WENDLING I et al. 2007. Características físicas e químicas de substratos para produção de mudas de llex paraguariensis St. Hil. Revista Árvore 31: 209-220.

WENDLING I et al. 2006. Substratos para produção de mudas de erva-mate em tubetes plásticos. Boletim de Pesquisa Florestal 52: 21-36. 